\title{
Are the Kihon Checklist and the Kaigo-Yobo Checklist compatible with the Frailty Index?
}

Gotaro Kojima, $\mathrm{MD}^{1,2}$; Yu Taniguchi, $\mathrm{PhD}^{2}$; Akihiko Kitamura, $\mathrm{MD}, \mathrm{PhD}^{2}$;

Shoji Shinkai, MD, PhD, $\mathrm{MPH}^{2}$;

${ }^{1}$ Department of Primary Care and Population Health, University College London, London, UK

${ }^{2}$ Research Team for Social Participation and Community Health, Tokyo Metropolitan Institute of Gerontology, Tokyo, Japan.

Corresponding Author:

Gotaro Kojima, MD

Department of Primary Care and Population Health

University College London (Royal Free Campus)

Rowland Hill Street,

London, NW3 2PF, UK

Phone: +44 (0)20 77940500

Fax: +44 (0)20 74726871

Email: gotarokojima@yahoo.co.jp 


\section{ABSTRACT}

Objectives: To explore comparability of Kihon Checklist (KCL) and Kaigo-Yobo Checklist (KYCL) to Frailty Index (FI) in predicting risks of long-term care insurance (LTCI) certification and/or mortality over three years.

Design: Prospective cohort study.

Setting and Participants: 1023 Japanese community-dwelling older adults from the Kusatsu Longitudinal Study of Aging and Health.

Measures: Frailty status was quantified at baseline using KCL, KYCL, and 32-deficit and 68-deficit FI. Relationships of the measures were examined using Spearman's rank correlation coefficients. Cox regression models examined the risk of new certification of LTCI or mortality according to KCL, KYCL, and FI. Predictive abilities of KCL and KYCL were compared with FI using area under the receiver operating characteristic curve (AUC), C statistics, net reclassification improvement (NRI), and integrated discrimination improvement (IDI).

Results: Mean age was 74.7 years and $57.6 \%$ were women. KCL and KYCL were significantly correlated to $32-\mathrm{FI}$ ( $\mathrm{r}=0.60$ and 0.36 , respectively) and to $68-\mathrm{FI}$ ( $\mathrm{r}=0.88$ and 0.61 , respectively). During the follow-up period, 92 participants (9\%) were newly certified for LTCI or died. Fully adjusted Cox models showed higher KCL, KYCL, 32-FI, and 68-FI were all significantly associated with elevated risks $(\mathrm{HR}=1.03,95 \% \mathrm{CI}=1.01-1.04, \mathrm{p}<0.001$; $\mathrm{HR}=1.04,95 \% \mathrm{CI}=1.02-1.05, \mathrm{p}<0.001 ; \mathrm{HR}=1.03,95 \% \mathrm{CI}=1.01-1.05, \mathrm{p}=0.001 ; \mathrm{HR}=1.04$, $95 \% \mathrm{CI}=1.02-1.06, \mathrm{p}<0.001$, respectively, per $1 / 100$ increase of max score). AUC and Cstatistics of KCL and KYCL were statistically not different from those of 32-FI and 68-FI. Predictive abilities of KCL were superior to 32-FI in NRI and IDI but inferior to 68-FI in category-free NRI, and those of KYCL were superior to 32-FI in IDI but inferior to 68-FI in NRI.

\section{Conclusions:}

Although KCL and KYCL include smaller numbers of items than standard FI, both tools were shown to be highly correlated with FI, significant predictors of LTCI certification and/or mortality, and compatible to FI in the risk prediction. 


\section{INTRODUCTION}

There is a growing number of researches regarding frailty mounting in the literature.

Although the concept of frailty has been widely accepted as a state of increased vulnerability to negative health outcomes, consensus regarding its standard definition has not been reached. ${ }^{1}$ Among the various frailty criteria proposed, the Kihon Checklist (KCL) and the Kaigo-Yobo Checklist (KYCL) have increasingly been used as frailty assessment tools. ${ }^{2-7}$ KCL and KYCL are both simple YES/NO questionnaires of 25 and 15 items, respectively, comprehensively covering multiple domains of important geriatric syndromes. These indices, initially developed in Japan, have now been translated into English and other languages and used in non-Japanese populations. ${ }^{8-13}$ Previous studies attempted to validate KCL and KYCL as frailty assessment tools and showed that both were highly correlated to frailty status $\mathrm{s}^{3,4}$ defined by the Fried's phenotype,${ }^{14}$ currently most frequently used frailty criteria. ${ }^{15}$

The Fried's phenotype operationalizes frailty as a biological syndrome, characterized by five specific physical symptoms: shrinking, exhaustion, weakness, slowness, and low physical activity. ${ }^{14}$ There is another commonly used frailty operationalization, the Frailty Index (FI). ${ }^{16}$ This approach, in contrast, considers disabilities, comorbidities, symptoms, and signs as deficits, and can quantify frailty status on a FI. ${ }^{16}$ In that KCL and KYCL include a wide range of activities of daily living (ADL), Instrumental ADL (IADL), physical function, nutritional status, oral function, housebound status, cognitive function, and depressive symptoms that can be used as a deficit to construct the FI, both indices may be more comparable to the conceptualization of the FI..$^{3,17,18}$ However, most of the previous studies using KCL or KYCL stratified the continuous total scores by cut-points and defined categorized frailty status, such as robust, prefrail, and frail, or non-frail and frail, based on the frailty phenotype. ${ }^{18}$ To our knowledge, there have been no studies in the literature comparing KCL and KYCL with the FI in risk prediction or discrimination. Thus we aimed to explore the potentials of KCL and KYCL as a FI and examined their comparability in relation to a standard FI in predicting risks of long-term care insurance (LTCI) certification and/or mortality in a Japanese elderly population.

\section{METHODS}

\section{Study setting and population}

The Kusatsu Longitudinal Study of Aging and Health is a cohort study of communitydwelling adults aged $\geq 65$ in Kusatsu town, Japan. ${ }^{19-21}$ Briefly, the study was launched in 2001, and has been following up on the participants by annual health check-ups and biennial health monitoring surveys.

Among 1254 individuals who participated in the health check-up in July 2014, 1048 (83.6\%) completed both KCL and KCYL questionnaires. Three participant who did not have enough deficit data to construct a FI, four who were already certified for the LTCI by 2014, and 18 who moved out or were lost for follow-up were excluded, leaving 1023 participants $(81.6 \%)$ as the final analytic sample. This study was approved by the ethics committee at $* * *$ and all participants provided written informed consent.

\section{Frailty assessment \\ Kihon Checklist}

This 25-item YES/NO questionnaire covers a wide range of domains: ADL ( $n=3)$, IADL $(n=3)$, social activities $(n=4)$, cognitive function $(n=3)$, depressive symptoms $(n=5)$, fallrelated issues $(n=2)$, nutritional status $(n=2)$, and oral function $(n=3) .{ }^{22}$ One point is given to 
each item and the total score ranges from 0-25, with a higher score indicative of greater frailty.

\section{Kaigo-Yobo Checklist}

KYCL is another YES/NO questionnaire of 15 items: ADL $(n=1)$, social activities ( $n=5)$, fallrelated issues $(n=3)$, nutritional status $(n=4)$, vision $(n=1)$, and hospitalization $(n=1) .{ }^{19}$ The total score ranges from $0-15$, with a higher score indicative of greater frailty.

\section{Frailty Index}

Two sets of FI (32 and 68 deficits) were generated according to the standard procedure. ${ }^{23}$ The first FI consisted of 32 deficits (32-FI) that were not included in KCL or KYCL. The second FI was based on these 32 deficits as well as 25 deficits from KCL and 15 deficits from KYCL. Four deficits from KYCL were excluded as identical or similar to items included in KCL, leaving 68 items (68-FI). (Supplementary Table)

\section{Follow-up and outcomes}

The participants were followed up through December 2017, for the composite outcome of newly certified LTCI or mortality. LTCI is a mandatory system of national social insurance that provides various types of formal care and support to eligible older adults aged $\geq 65$ with disabilities. $^{24,25}$ The certification processes include functional disability assessment and a reference letter from attending doctors. ${ }^{26}$ For a participant who was certified for LTCI and died during the follow-up period, LTCI certification was used as an event. A LTCI application date was used for the LTCI certification outcome. These outcomes were monitored using the local resident registries and LTCI system databases.

\section{Covariates}

Baseline covariates used for adjustment were age, gender, smoking, alcohol use, and education, which were considered to have effects on the relationship between frailty and loss of independency.

\section{Statistical Analysis}

Relationships among KCL, KYCL, 32-FI, and 68-FI were examined using Spearman's rank correlation coefficients since distribution of the four indices was similarly skewed to the right.

Cox regression models examined the risk of new certification of LTCI or mortality according to KCL, KYCL, 32-FI, and 68-FI. For comparison, hazard ratios and 95\% confidence intervals (CI) for these frailty measures were calculated per 1/100 of the maximum scores (0.25 for KCL, 0.15 for KYCL, and 0.01 for FI).

Predictive abilities of KCL and KYCL were separately compared with 32-FI using three measures: (1) changes in the area under the receiver operating characteristic (ROC) curve (AUC) and C statistics, (2) categorical and category-free net reclassification improvement (NRI), and (3) integrated discrimination improvement (IDI). ${ }^{27}$ The ROC curves were depicted for KCL, KYCL, 32-FI, and 68-FI, for each of which AUC was calculated. C statistics adjusted for age and gender and ones adjusted for age, gender, education, smoking, and alcohol use were calculated. NRI quantifies how better KCL or KYCL correctly reclassified individuals with and without the events, which were LTCI certification or mortality in this case. Cut-points for the predicted probability quartiles of 32-FI were used for the categorical NRI. IDI is the difference of two models' discrimination slopes, which are 
calculated as a difference of mean predicted probabilities between those with and without events.

All statistical analyses were conducted using StataSE 14 (StataCorp LP, College Station, TX) and SAS software (Version 9.4, SAS institute, Cary, NC). Statistical significance was based on 2-tailed $\mathrm{p}$ value of $<0.05$.

\section{RESULTS}

Mean age was 74.7 years and 57.6\% were women. Mean scores of KCL and KYCL were 3.7 and 1.5 , respectively. Means of 32-FI and 68-FI were 0.15 and 0.14 , respectively.

Both KCL and KYCL were significantly correlated to 32-FI, with correlation coefficients of 0.60 and 0.36 (both $\mathrm{p}<0.0001$ ). Correlation between KCL and KYCL was also significant (Spearman's rho $=0.52, \mathrm{p}<0.0001$ ). 68-FI, which combined all components of the three others, was significantly associated with KCL, KYCL, and 32-FI (Spearman's rho=0.88, 0.61, and 0.87 , all $\mathrm{p}<0.0001)$.

During the follow-up period, 92 participants (9\%) were newly certified for LTCI $(n=52)$ or died (n=40). Higher KCL, KYCL, 32-FI, and 68-FI were all significantly associated with elevated risks of LTCI certification or mortality (fully adjusted models: $\mathrm{HR}=1.03, \mathrm{HR}=1.04$, $\mathrm{HR}=1.03,95 \% \mathrm{CI}=1.01-1.05, \mathrm{HR}=1.04$, respectively, all $\mathrm{p}<0.001)$. (Table 1)

Figures A and B show ROC curves of KCL, KYCL, 32-FI, and 68-FI predicting composite outcomes of incident LTCI certification or mortality. AUC of KCL, KYCL, 32-FI, and 68-FI were $0.675,0.644,0.637$, and 0.678 , respectively, suggesting "poor" predictive power. The cut-points with highest Youden's index for KCL and KYCL were 8 and 4.

AUC, age- and gender-adjusted and fully adjusted C statistics of KCL, KYCL, 32-FI, and 68FI are summarized and compared in Table 2. AUC, age- and gender-adjusted and fully adjusted $\mathrm{C}$ statistics did not show any significant difference in predictive ability of KCL and KYCL against 32-FI and 68-FI. While KCL reclassified participants with and without the events significantly better than 32-FI in category-free (by 26.2\%) and categorical (by 15.7\%) NRI, and IDI, KCL was inferior to 68 -FI significantly in category-free NRI by $1.4 \%$ and nonsignificantly in categorical NRI by $9.8 \%$ and IDI.

While predictive ability of KYCL was shown to be non-significantly higher than 32-FI in category-free and categorical NRI and significantly higher than in IDI, that of 68-FI was superior significantly in category-free (by 30.3\%) and categorical (by 12.2\%) and nonsignificantly in IDI.

\section{DISCUSSION}

We compared risk-predictive abilities of KCL and KYCL as a continuous score in relation to FI, using an array of measures including Cox regression models, ROC curve, AUC, C statistics, NRI, and IDI in 1023 Japanese community-dwelling older people and demonstrated that KCL and KYCL were significant predictors of LTCI certification and/or mortality and their predictive abilities were compatible with FI.

It is noteworthy that KCL consisting of only 25 items was shown to have better overall predictive abilities than 32-FI, mostly significantly. In addition, the predictive ability of KCL was comparable to that of 68-FI, which means adding 43 deficits to KCL did not much 
improve the risk prediction. The 25 items of KCL may be a balanced collection of major core deficits from various domains, while 32 deficits used by 32-FI were leftover ones not used by KCL and KYCL and thus may be weaker predictors of adverse outcomes. KYCL includes as few as 15 items, less than half of deficits required for standard FI. ${ }^{23}$ Therefore, it was rather expected the predictive ability of KYCL was significantly lower than that of 68-FI in most measures. However, predictive ability measures of KYCL were mostly better than 32-FI although the differences were small and mostly did not reach statistical significance.

On top of their risk-predictive abilities compatible to FI, KCL and KYCL have unique features. While FI can flexibly be constructed based on an arbitrary set of deficits, which may hinder precise comparisons between FI with different deficits across cohorts or, even in the same cohort. ${ }^{23}$ As items are fixed in KCL and KYCL, frailty status can be compared without constraints of different cohorts or time points. KCL and KYCL don't require special equipment, therefore are quicker to conduct than FI. ${ }^{17}$ Furthermore, they consist of all selfreported items and can be administered by non-healthcare professionals or by mail, email, or phone.

Although FI can effectively quantify overall frailty status, it may be much harder to identify which component is the leading cause of frailty. The items used in KCL and KYCL are grouped into several domains of geriatric syndromes. Therefore, it may be easier to identify the primary cause of frailty and to prepare for specific future events, ${ }^{28-30}$ as well as implement tailored and focused interventions. ${ }^{5}$

Strengths of this study include use of various statistical measures conducted to compare predictive abilities of KCL and KYCL with that of FI in a prospective cohort study, a wide range of covariates used for adjustment when appropriate, and comparison with two types of FI, one of which (32-FI) consisted of only deficits not included KCL or KYCL and the other (68-FI) combined all deficits of KCL, KYCL, and 32-FI.

Our findings should be interpreted with caution. First, the sample size is relatively small and the population used is limited to Japanese community-dwelling older people as in the previous studies. ${ }^{3-7}$ Therefore, our findings may not be generalizable to other populations and more studies are needed cross-culturally. Second, we used the composite outcome of LTCI certification and/or mortality as a surrogate marker of loss of independence. Although LTCI is an established national system in Japan, it may be difficult to compare our findings with that of studies done in other countries with different long-term care systems.

\section{CONCLUSION}

Although KCL and KYCL include smaller numbers of items than a standard FI, both tools were shown to be highly correlated with FI, significant predictors of loss of independence, and compatible to FI in the risk prediction. In addition to their usefulness and feasibility, total scores of KCL and KYCL can be potentially used as a FI to assess and quantify frailty status. Compatibility of KCL and KYCL should be further confirmed by future research, focusing on other outcomes and using different ethnic populations.

\section{ACKNOWLEDGEMENT}

We are grateful to the participants and municipal officers in Kusatsu town. This study was supported by grants from ***, JST/RISTEX, Grants-In-Aid for Scientific Research (B) JP20390190, (B) JP21390212, (B) JP24390173, and (B) JP26310111 from the Ministry of Education, Culture, Sports, Science and Technology, Japan. 


\section{Conflict of Interest}

The authors have no conflicts in the cover letter as well as in the manuscript, as noted above.

\section{Author Contributions}

Study concept and design: GK and YT. Acquisition of data: YT, AK and SS. Analysis and interpretation of data: GK, YT, AK and SS. Drafting the article: GK. Revising the article critically for important intellectual content: GK, YT, AK and SS. Final approval of the version to be published: GK, YT, AK and SS.

\section{Sponsor's Role}

None

\section{REFERENCES}

1. Clegg A, Young J, Iliffe S, et al. Frailty in elderly people. Lancet (London, England) 2013;381:752-762.

2. Sewo Sampaio PY, Sampaio RA, Yamada M, Arai H. Systematic review of the Kihon Checklist: Is it a reliable assessment of frailty? Geriatrics \& gerontology international 2016;16:893-902.

3. Satake S, Senda K, Hong YJ, et al. Validity of the Kihon Checklist for assessing frailty status. Geriatrics \& gerontology international 2016;16:709-715.

4. Shinkai S, Watanabe N, Yoshida H, et al. [Validity of the "Kaigo-Yobo Check-List" as a frailty index]. [Nihon koshu eisei zasshi] Japanese journal of public health 2013;60:262-274.

5. Satake S, Shimokata H, Senda K, et al. Validity of Total Kihon Checklist Score for Predicting the Incidence of 3-Year Dependency and Mortality in a CommunityDwelling Older Population. Journal of the American Medical Directors Association 2017;18:552 e551-552 e556.

6. Shinkai S, Watanabe N, Yoshida H, et al. [Research on screening for frailty: development of "the Kaigo-Yobo Checklist"]. [Nihon koshu eisei zasshi] Japanese journal of public health 2010;57:345-354.

7. Ogawa K, Fujiwara Y, Yoshida H, et al. [The validity of the "Kihon Check-list" as an index of frailty and its biomarkers and inflammatory markers in elderly people]. Nihon Ronen Igakkai zasshi. Japanese journal of geriatrics 2011;48:545-552.

8. Kim YP, Kim S, Joh JY, Hwang HS. Effect of interaction between dynapenic component of the European working group on sarcopenia in older people sarcopenia criteria and obesity on activities of daily living in the elderly. Journal of the American Medical Directors Association 2014;15:371 e371-375.

9. Sewo Sampaio PY, Sampaio RA, Coelho Junior HJ, et al. Differences in lifestyle, physical performance and quality of life between frail and robust Brazilian community-dwelling elderly women. Geriatrics \& gerontology international 2016;16:829-835.

10. Maseda A, Lorenzo-Lopez L, Lopez-Lopez R, et al. Spanish translation of the Kihon Checklist (frailty index). Geriatrics \& gerontology international 2017;17:515-517.

11. Jang IY, Jung HW, Lee CK, et al. Korean version of the Fatigue, Resistance, Ambulation, Illnesses and Loss of weight questionnaire versus the Modified Kihon Checklist for Frailty Screening in Community-Dwelling Older Adults: The Aging Study of PyeongChang Rural Area. Geriatrics \& gerontology international 2017;17:2046-2052. 
12. Sewo Sampaio PY, Sampaio RA, Yamada M, et al. Validation and translation of the Kihon Checklist (frailty index) into Brazilian Portuguese. Geriatrics \& gerontology international 2014;14:561-569.

13. Hwang HS, Yoon JL, Park BJ, et al. The validity and reliability of the Kaigo-Yobo checklist in Korean elderly. Journal of the Korean Geriatrics Society 2012;16:121-132.

14. Fried LP, Tangen CM, Walston J, et al. Frailty in older adults: evidence for a phenotype. The journals of gerontology. Series A, Biological sciences and medical sciences 2001;56:M146-156.

15. Bouillon K, Kivimaki M, Hamer M, et al. Measures of frailty in population-based studies: an overview. BMC geriatrics 2013;13:64.

16. Mitnitski AB, Mogilner AJ, Rockwood K. Accumulation of deficits as a proxy measure of aging. TheScientificWorldJournal 2001;1:323-336.

17. Dent E, Kowal P, Hoogendijk EO. Frailty measurement in research and clinical practice: A review. European journal of internal medicine 2016;31:3-10.

18. Kojima G, Iliffe S, Taniguchi Y, et al. Prevalence of frailty in Japan: A systematic review and meta-analysis. Journal of epidemiology 2017;27:347-353.

19. Shinkai S, Yoshida H, Taniguchi Y, et al. Public health approach to preventing frailty in the community and its effect on healthy aging in Japan. Geriatrics \& gerontology international 2016;16 Suppl 1:87-97.

20. Taniguchi Y, Yoshida H, Fujiwara Y, et al. A prospective study of gait performance and subsequent cognitive decline in a general population of older Japanese. The journals of gerontology. Series A, Biological sciences and medical sciences 2012;67:796-803.

21. Murayama H, Shinkai S, Nishi M, et al. Albumin, Hemoglobin, and the Trajectory of Cognitive Function in Community-Dwelling Older Japanese: A 13-Year Longitudinal Study. The journal of prevention of Alzheimer's disease 2017;4:93-99.

22. Arai H, Satake S. English translation of the Kihon Checklist. Geriatrics \& gerontology international 2015;15:518-519.

23. Searle SD, Mitnitski A, Gahbauer EA, et al. A standard procedure for creating a frailty index. BMC geriatrics 2008;8:24.

24. Ikegami N. Public long-term care insurance in Japan. Jama 1997;278:1310-1314.

25. Tsutsui T, Muramatsu N. Care-needs certification in the long-term care insurance system of Japan. Journal of the American Geriatrics Society 2005;53:522-527.

26. Moriyama Y, Tamiya N, Kamimura A, et al. Doctors' opinion papers in long-term care need certification in Japan: comparison between clinic and advanced treatment hospital settings. Public Policy Admin Res 2014;4:31-37.

27. Pencina MJ, D'Agostino RB, Pencina KM, et al. Interpreting incremental value of markers added to risk prediction models. American journal of epidemiology 2012;176:473-481.

28. Fukutomi E, Okumiya K, Wada T, et al. Importance of cognitive assessment as part of the "Kihon Checklist" developed by the Japanese Ministry of Health, Labor and Welfare for prediction of frailty at a 2-year follow up. Geriatrics \& gerontology international 2013;13:654-662.

29. Suzuki N, Makigami K, Goto A, et al. [Comparison of ability-based and performancebased IADL evaluation of community-dwelling elderly using the Kihon Checklist and TMIG Index of Competence]. Nihon Ronen Igakkai zasshi. Japanese journal of geriatrics 2007;44:619-626.

30. Kato C, Fujita R, Ida K. [Participant characteristics and intervention effects of a program to improve the physical function in community-dwelling frail elderly 
subjects]. Nihon Ronen Igakkai zasshi. Japanese journal of geriatrics 2013;50:804811. 
Table 1. Univariate and multivariate Cox regression models predicting 4-year incident mortality or long-term care insurance certification according to Kihon Checklist, Kaigo-Yobo Checklist, 32-deficit Frailty Index, and 68-deficit Frailty Index $(\mathrm{N}=1023)$.*

\begin{tabular}{|l|c|c|c|c|c|}
\hline & Unadjusted model & & Fully adjusted model $\dagger$ & \\
\hline \multicolumn{1}{|c|}{ Variable } & Hazard ratio (95\%CI) & p value & & Hazard ratio (95\% $\%$ CI & p value \\
\hline Kihon Checklist score & $1.04(1.03-1.05)$ & $<0.001$ & & $1.03(1.01-1.04)$ & $<0.001$ \\
\hline Kaigo-Yobo Checklist score & $1.05(1.04-1.06)$ & $<0.001$ & & $1.04(1.02-1.05)$ & $<0.001$ \\
\hline 32-deficit Frailty Index & $1.04(1.03-1.05)$ & $<0.001$ & & $1.03(1.01-1.05)$ & 0.001 \\
\hline 68-deficit Frailty Index & $1.05(1.04-1.07)$ & $<0.001$ & & $1.04(1.02-1.06)$ & $<0.001$ \\
\hline
\end{tabular}

* 32-deficit Frailty Index does not include deficits included in Kihon Checklist or KaigoYobo Checklist. 68-deficit Frailty Index includes the 32 deficits and all 36 deficits included in Kihon Checklist and Kaigo-Yobo Checklist. Hazard ratios for 32-deficit and 68-deficit Frailty Indexes were per 0.01 increase. Hazard ratios for Kihon Checklist and Kaigo-Yobo Checklist scores were per 0.25 and 0.15 increase, respectively, to be comparable with Frailty Index (corresponding to 0.01 increase in Frailty Index). $\dagger$ Adjusted for age, gender, education (year), smoking, and alcohol. 
Table 2. Risk prediction abilities of Kihon Checklist and Kaigo-Yobo Checklist compared with 32-deficit and 68-deficit Frailty Indices*

\begin{tabular}{|c|c|c|c|}
\hline & Kihon Checklist & $\begin{array}{c}\text { 32-deficit } \\
\text { Frailty Index* }\end{array}$ & $\begin{array}{c}\text { 68-deficit } \\
\text { Frailty Index* }\end{array}$ \\
\hline Area under the curve $(95 \% \mathrm{CI})$ & $0.675(0.614-0.737)$ & $0.637(\mathrm{p}=0.16)$ & $0.678(\mathrm{p}=0.82)$ \\
\hline C statistic, age- and gender adjusted (95\%CI) & $0.796(0.747-0.844)$ & $0.792(\mathrm{p}=0.61)$ & $0.799(\mathrm{p}=0.49)$ \\
\hline C statistic, fully adjusted ${ }^{\dagger}(95 \% \mathrm{CI})$ & $0.821(0.772-0.869)$ & $0.809(\mathrm{p}=0.17)$ & $0.821(\mathrm{p}=0.95)$ \\
\hline Category-free NRI & - & $0.262(\mathrm{p}=0.02)$ & $-0.014(\mathrm{p}=0.02)$ \\
\hline Categorical NRI ${ }^{\ddagger}$ & - & $0.157(\mathrm{p}=0.04)$ & $-0.098(\mathrm{p}=0.37)$ \\
\hline $\mathrm{IDI}^{\dagger}$ & - & $0.017(\mathrm{p}=0.05)$ & $-0.004(\mathrm{p}=0.94)$ \\
\hline & Kaigo-Yobo Checklist & $\begin{array}{l}\text { vs. 32-deficit } \\
\text { Frailty Index* }\end{array}$ & $\begin{array}{l}\text { vs. 68-deficit } \\
\text { Frailty Index* }\end{array}$ \\
\hline Area under the curve $(95 \% \mathrm{CI})$ & $0.644(0.579-0.709)$ & $0.637(\mathrm{p}=0.85)$ & $0.678(\mathrm{p}=0.17)$ \\
\hline $\mathrm{C}$ statistic, age- and gender adjusted (95\%CI) & $0.798(0.747-0.848)$ & $0.792(\mathrm{p}=0.59)$ & $0.799(\mathrm{p}=0.81)$ \\
\hline C statistic, fully adjusted ${ }^{\dagger}(95 \% \mathrm{CI})$ & $0.822(0.771-0.872)$ & $0.809(\mathrm{p}=0.27)$ & $0.821(\mathrm{p}=0.94)$ \\
\hline Category-free NRI & - & $0.091(\mathrm{p}=0.40)$ & $-0.303(\mathrm{p}=0.01)$ \\
\hline Categorical NRI ${ }^{\ddagger}$ & - & $0.011(\mathrm{p}=0.90)$ & $-0.122(\mathrm{p}=0.09)$ \\
\hline $\mathrm{IDI}^{+}$ & - & $0.026(\mathrm{p}=0.02)$ & $-0.005(\mathrm{p}=0.57)$ \\
\hline
\end{tabular}

CI: confidence interval, IDI: Integrated discrimination improvement, NRI: Net reclassification improvement

* p value for difference from Kihon Checklist or comparison with Kihon Checklist.

${ }^{\dagger}$ Adjusted for age, gender, education, smoking, and alcohol.

$\$$ Positive value suggests Kihon Checklist or Kaigo-Yobo Checklist has better predictive ability. 
Figures A and B. Receiver operating characteristic curves of Kihon Checklist and KaigoYobo Checklist in comparison with 32-deficit Frailty Index (A) and 68-deficit Frailty Index (B) to predict long-term care insurance certification or mortality.

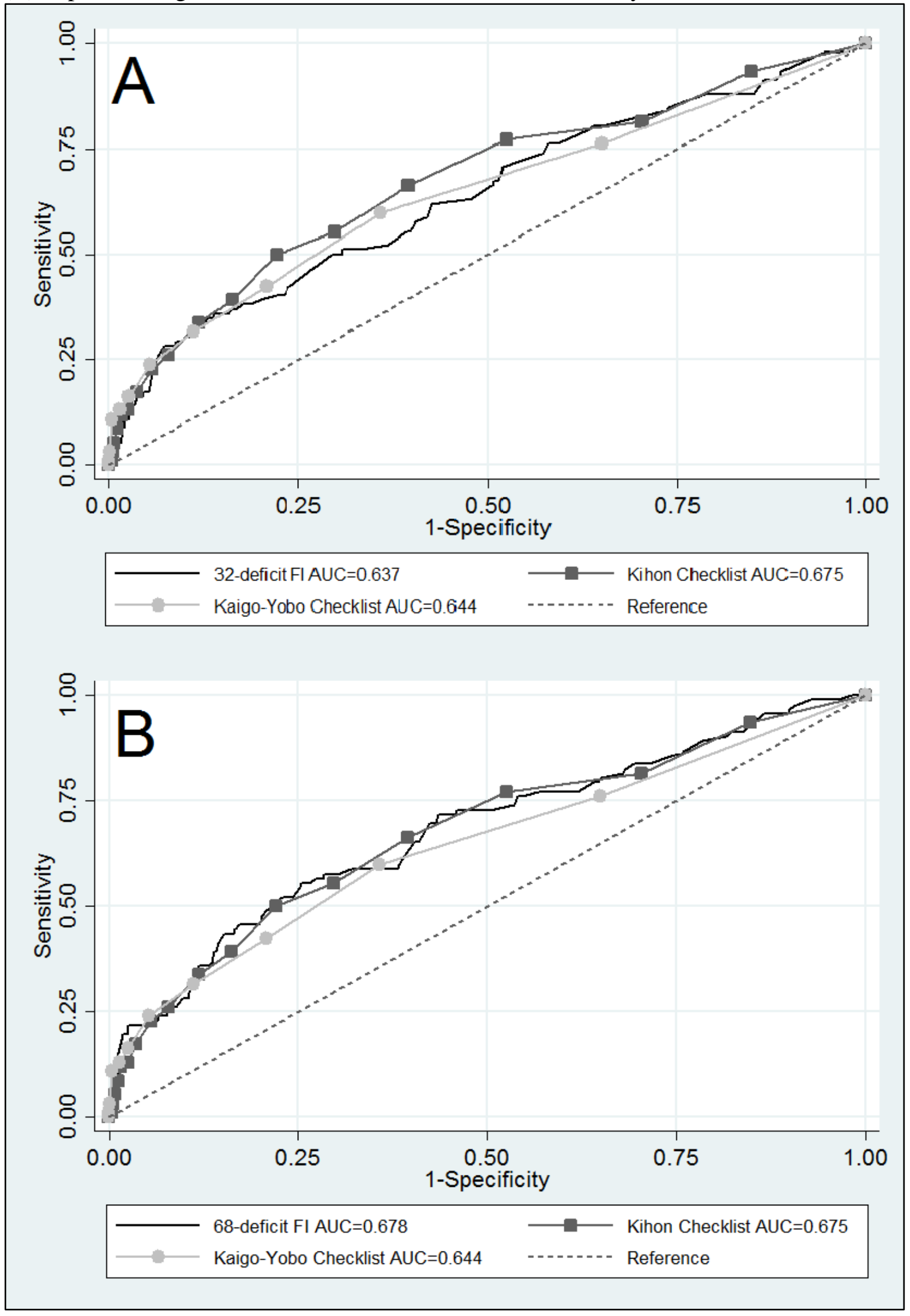


Supplementary Table. List of deficits for constructing frailty index

\begin{tabular}{|c|c|c|}
\hline & variable & coding \\
\hline & Kihon Checklist $(\mathrm{n}=25)$ & \\
\hline 1 & Do you go out by bus or train by yourself? & $\mathrm{Yes}=0, \mathrm{No}=1$ \\
\hline 2 & $\begin{array}{l}\text { Do you go shopping to buy daily necessities by } \\
\text { yourself? }\end{array}$ & Yes $=0, \mathrm{No}=1$ \\
\hline 3 & $\begin{array}{l}\text { Do you manage your own deposits and savings at the } \\
\text { bank? }\end{array}$ & Yes $=0, \mathrm{No}=1$ \\
\hline 4 & Do you sometimes visit your friends? & $\mathrm{Yes}=0, \mathrm{No}=1$ \\
\hline 5 & Do you give advice to your family or friends? & Yes $=0, \mathrm{No}=1$ \\
\hline 6 & $\begin{array}{l}\text { Are you able to climb up stairs without using handrails } \\
\text { or wall for support? }\end{array}$ & $\mathrm{Yes}=0, \mathrm{No}=1$ \\
\hline 7 & Can you stand up from a chair without support? & $\mathrm{Yes}=0, \mathrm{No}=1$ \\
\hline 8 & Can you keep walking for 15 minutes? & $\mathrm{Yes}=0, \mathrm{No}=1$ \\
\hline 9 & Have you experienced a fall in the past year? & $\mathrm{Yes}=1, \mathrm{No}=0$ \\
\hline 10 & Do you have a fear of falling while walking? & $\mathrm{Yes}=1, \mathrm{No}=0$ \\
\hline 11 & Have you lost $2-3 \mathrm{~kg}$ in the past 6 months? & Yes $=1, \mathrm{No}=0$ \\
\hline 12 & Height and weight to calculate BMI & $\mathrm{BMI}<18.5=1, \mathrm{BMI}>=18.5=0$ \\
\hline 13 & $\begin{array}{l}\text { Do you have more difficulty chewing solid food than } 6 \\
\text { months ago? }\end{array}$ & $\mathrm{Yes}=1, \mathrm{No}=0$ \\
\hline 14 & $\begin{array}{l}\text { Do you have choking or coughing while drinking tea } \\
\text { or soup? }\end{array}$ & $\mathrm{Yes}=1, \mathrm{No}=0$ \\
\hline 15 & $\begin{array}{l}\text { Do you have dry month or difficulty swallowing food } \\
\text { because of dry mouth? }\end{array}$ & $\mathrm{Yes}=1, \mathrm{No}=0$ \\
\hline 16 & Do you go out at least once a week? & Yes $=0, \mathrm{No}=1$ \\
\hline 17 & Do you go out less often than last year? & $\mathrm{Yes}=1, \mathrm{No}=0$ \\
\hline 18 & $\begin{array}{l}\text { Do people point out your forgetfulness, such as "you } \\
\text { always ask the same question" }\end{array}$ & $\mathrm{Yes}=1, \mathrm{No}=0$ \\
\hline 19 & Can you look up phone numbers and make a call? & $\mathrm{Yes}=0, \mathrm{No}=1$ \\
\hline 20 & $\begin{array}{l}\text { Do you sometimes find yourself not knowing what } \\
\text { month or date it is? }\end{array}$ & $\mathrm{Yes}=1, \mathrm{No}=0$ \\
\hline 21 & $\begin{array}{l}\text { In the past } 2 \text { weeks, you have felt a lack of fulfilment } \\
\text { in your life. }\end{array}$ & $\mathrm{Yes}=1, \mathrm{No}=0$ \\
\hline 22 & $\begin{array}{l}\text { In the past } 2 \text { weeks, you have less enjoyed things you } \\
\text { used to than before. }\end{array}$ & $\mathrm{Yes}=1, \mathrm{No}=0$ \\
\hline 23 & $\begin{array}{l}\text { In the past } 2 \text { weeks, you have felt more difficulty or } \\
\text { trouble in doing what you could do easily before. }\end{array}$ & $\mathrm{Yes}=1, \mathrm{No}=0$ \\
\hline 24 & $\begin{array}{l}\text { In the past } 2 \text { weeks, you do not feel you are a useful } \\
\text { person. }\end{array}$ & $\mathrm{Yes}=0, \mathrm{No}=1$ \\
\hline 25 & $\begin{array}{l}\text { In the past } 2 \text { weeks, you have felt tired without a } \\
\text { reason. }\end{array}$ & $\mathrm{Yes}=1, \mathrm{No}=0$ \\
\hline & Kaigo-Yobo Checklist $(\mathrm{n}=15)$ & \\
\hline 1 & Do you usually stay at home all day long? & Yes $=1, \mathrm{No}=0$ \\
\hline 2 & How often do you usually go out? & $\begin{array}{l}\text { More than once per } 2-3 \text { days }=0 \text {, Less than } \\
\text { once a week }=1\end{array}$ \\
\hline 3 & Do you have any hobby? & $\mathrm{Yes}=0, \mathrm{No}=1$ \\
\hline 4 & Do you have neighbors who you can talk closely with? & $\mathrm{Yes}=0, \mathrm{No}=1$ \\
\hline 5 & $\begin{array}{l}\text { Besides your neighbors, do you have close friends, } \\
\text { families, or relatives who you visit? }\end{array}$ & Yes $=0, \mathrm{No}=1$ \\
\hline
\end{tabular}




\begin{tabular}{|c|c|c|}
\hline 6 & Have you experienced a fall in the past year? & $\mathrm{Yes}=1, \mathrm{No}=0$ \\
\hline 7 & Can you walk for $1 \mathrm{~km} ?$ & Yes $=0, \mathrm{No}=1$ \\
\hline 8 & Can you see things clearly? (with glasses if necessary) & $\begin{array}{l}\text { Without difficulty }=0 \text {, With difficulty or can } \\
\text { not }=1\end{array}$ \\
\hline 9 & Do you often slip or stumble at home? & Yes $=1, \mathrm{No}=0$ \\
\hline 10 & $\begin{array}{l}\text { Do you refrain from going out because of fear of } \\
\text { falling? }\end{array}$ & $\mathrm{Yes}=1, \mathrm{No}=0$ \\
\hline 11 & Have you been hospitalized in the past year? & $\mathrm{Yes}=1, \mathrm{No}=0$ \\
\hline 12 & Do you have appetite these days? & $\mathrm{Yes}=0, \mathrm{No}=1$ \\
\hline 13 & $\begin{array}{l}\text { Do you have any difficulty chewing? (even with a } \\
\text { denture) }\end{array}$ & Yes $=1, \mathrm{No}=0$ \\
\hline 14 & Have you lost $3 \mathrm{~kg}$ or more in the past 6 months? & $\mathrm{Yes}=1, \mathrm{No}=0$ \\
\hline \multirow[t]{2}{*}{15} & $\begin{array}{l}\text { Do you think you have lost muscle or fat in the past } 6 \\
\text { months? }\end{array}$ & $\mathrm{Yes}=1, \mathrm{No}=0$ \\
\hline & 32-deficit Frailty Index $(n=32)$ & \\
\hline 1 & Self-rated general health & Very good $=0$, Good $=1 / 3$, Fair $=2 / 3$, Poor $=1$ \\
\hline 2 & How is your hearing? & $\begin{array}{l}\text { No difficulty }=0, \text { With loud voice }=1 / 3 \text {, Only } \\
\text { with loud voice in an ear }=2 / 3 \text {, Almost can't }=1\end{array}$ \\
\hline 3 & Can you walk? & Can walk $=0$, Can with support $=0.5$, Can't $=1$ \\
\hline 4 & Can you eat by yourself? & $\begin{array}{l}\text { No difficulty=0, With some preparation=0.5, } \\
\text { Can' } t=1\end{array}$ \\
\hline 5 & Can you bathe by yourself? & No difficulty $=0$, With support $=0.5$, Can't $=1$ \\
\hline 6 & Can you dress yourself? & No difficulty $=0$, With support $=0.5$, Can' $\mathrm{t}=1$ \\
\hline 7 & Can you use toilet by yourself? & No difficulty $=0$, With support $=0.5$, Can' $t=1$ \\
\hline 8 & Do you sometimes fail to make it to toilet? & $\begin{array}{l}\text { No }=0 \text {, sometimes }=0.5 \text {, always or on urinary } \\
\text { catheter }=1\end{array}$ \\
\hline 9 & Can you fill out forms for pension etc.? & $\mathrm{Yes}=0, \mathrm{No}=1$ \\
\hline 10 & Can you visit someone in the hospital? & $\mathrm{Yes}=0, \mathrm{No}=1$ \\
\hline 11 & Can you prepare meals by yourself? & $\mathrm{Yes}=0, \mathrm{No}=1$ \\
\hline 12 & Can you make payment for bills? & $\mathrm{Yes}=0, \mathrm{No}=1$ \\
\hline 13 & Hypertension & Present $=1$, Absent $=0$ \\
\hline 14 & Hyperlipidemia & Present $=1$, Absent $=0$ \\
\hline 15 & Diabetes & Present $=1$, Absent $=0$ \\
\hline 16 & Heart disease & Present $=1$, Absent $=0$ \\
\hline 17 & Stroke & Present $=1$, Absent $=0$ \\
\hline 18 & Are you basically satisfied with your life? & $\mathrm{Yes}=0, \mathrm{No}=1$ \\
\hline 19 & $\begin{array}{l}\text { Have you dropped many of your activities and } \\
\text { interests? }\end{array}$ & Yes $=1, \mathrm{No}=0$ \\
\hline 20 & Do you feel that your life is empty? & $\mathrm{Yes}=1, \mathrm{No}=0$ \\
\hline 21 & Do you often get bored? & $\mathrm{Yes}=1, \mathrm{No}=0$ \\
\hline 22 & Are you in good spirits most of the time? & $\mathrm{Yes}=0, \mathrm{No}=1$ \\
\hline 23 & $\begin{array}{l}\text { Are you afraid that something bad is going to happen } \\
\text { to you? }\end{array}$ & Yes $=1, \mathrm{No}=0$ \\
\hline 24 & Do you feel happy most of the time? & Yes $=0, \mathrm{No}=1$ \\
\hline 25 & Do you often feel helpless? & $\mathrm{Yes}=1, \mathrm{No}=0$ \\
\hline 26 & $\begin{array}{l}\text { Do you prefer to stay at home, rather than going out } \\
\text { and doing new things? }\end{array}$ & $\mathrm{Yes}=1, \mathrm{No}=0$ \\
\hline 27 & $\begin{array}{l}\text { Do you feel you have more problems with memory } \\
\text { than most? }\end{array}$ & $\mathrm{Yes}=1, \mathrm{No}=0$ \\
\hline
\end{tabular}




\begin{tabular}{|l|l|l|}
\hline 28 & Do you think it is wonderful to be alive now? & Yes $=0$, No $=1$ \\
\hline 29 & Do you feel pretty worthless the way you are now? & Yes $=1$, No $=0$ \\
\hline 30 & Do you feel full of energy? & Yes $=0$, No $=1$ \\
\hline 31 & Do you feel that your situation is hopeless? & Yes $=1$, No=0 \\
\hline 32 & $\begin{array}{l}\text { Do you think that most people are better off than you } \\
\text { are? }\end{array}$ & Yes $=1$, No=0 \\
\hline
\end{tabular}

BMI: Body mass index

68-deficit Frailty Index was constructed based on Kihon Checklist, Kaigo-Yobo Checklist and 32-deficit Frailty Index, with 4 duplicate items in Kaigo-Yobo Checklist excluded. 